\title{
THE USE OF SPECT/CT IN THE EVALUATION OF HETEROTOPIC OSSIFICATION IN PARA/TETRAPLEGICS
}

\author{
Mauricio Coelho Lima ${ }^{1}$, Marcus Ceregati Passarelli ${ }^{1}$, Virgillo Dario ${ }^{1}$, Bruno Rodrigues Lebani ${ }^{1}$, \\ Paulo Henrique Silva Monteiro ${ }^{1}$, Celso Dario Ramos ${ }^{1}$
}

\begin{abstract}
Objective: To evaluate the stage of maturation and the metabolism of neurogenic heterotopic ossification by using SPECT/CT. Methods: A total of 12 medical records of patients with spinal cord injury, all of them classified according to the ASIA protocol (disability scale from the American Spinal Injury Association) in complete lesion (A) and partial lesions (B, C and D) and registered at the Laboratory of Biomechanics and Rehabilitation of the Locomotor System, were submitted to SPECT/CT evaluation. Results: Sixteen hips with heterotopic ossification observed in X-ray were studied and only two (12.5\%) had high osteoblastic
\end{abstract}

activity. Five hips showed medium activity, three (18.75\%) low activity and six (37.5\%) did not present any activity detected by SPECT/CT. Conclusion: SPECT/CT helps to determinate which patients have a greater risk of relapse after surgical resection, proving to be a useful imaging study in preoperative evaluation that can be used to determinate the postoperative prognosis of these patients. Level of Evidence III, Investigating a Diagnostic Test.

Keywords: Ossification, heterotopic. Paraplegia. Tetraplegia. Tomography, emission-computed, single-photon.

Citation: Lima MC, Passarelli MC, Dario V, Lebani BR, Monteiro PHS, Ramos CD. Use of SPECT/CT in the evaluation of heterotopic ossification in para/tetraplegics. Acta Ortop Bras. [online]. 2014;22(1):12-6. Available from URL: http://www.scielo.br/aob.

\section{INTRODUCTION}

The term heterotopic ossification ( $\mathrm{HO}$ ), or myositis ossificans, is characterized by a process of abnormal osteogenesis in non-skeletal tissues, resulting from an initial inflammatory process. Such bone formations are not considered neoplasms and can affect all types of soft tissues. ${ }^{1-4}$ In general, they originate from post-traumatic complications and may result in loss of range of motion and ankylosis in the more advanced stages of the disease, with serious damage to rehabilitation process. ${ }^{5,6}$ Being asymptomatic, $\mathrm{HO}$ is a major concern in the care of patients with spinal cord injury. ${ }^{7}$ Heterotopic ossification is considered a keyword to access to computerized databases worldwide. The term heterotopic calcification is related to other forms, non-orthopedic, of alterations by deposition of calcium salts in soft tissues throughout the body. ${ }^{8}$ The "myositis ossificans" nomenclature is used incorrectly, given that this is not a process restricted to muscles and often presents only mild inflamação. ${ }^{9}$ The origin of $\mathrm{HO}$, its clinical presentation, location, and isolated or progressive occurrence shall define the type of ossification to occur, being classified into four types: 1 . Post- traumatic (fractures, total hip arthroplasty or direct muscle trauma); 2. Neurogenic (spinal cord injury or non-traumatic central nervous system injury); 3. Myositis; 4.Progressive fibrodysplasia ossificans. ${ }^{10,11}$ The physiopathological analysis shows the need for the presence of three factors for the development of $\mathrm{HO}$ : osteogenic precursor cells, inducers and permissive environment. This combination allows the differentiation of mesenchymal cells into osteogenic cells. ${ }^{12}$ Several bone morphogenetic proteins are essential for mesenchymal cell differentiation into osteogenic cells, especially BMP-4. Under normal conditions, such a protein is subjected to a negative feedback due to antagonists such as noggin, gremlin, chordin and follistatin. With reduced inhibitory response of these substances, BMP-4 is overexpressed by increasing the amount of osteogenic cells. This mechanism is responsible for the evolution of progressive fibrodysplasia ossificans. The most detailed and in-depth knowledge about its pathophysiology may significantly contribute to provide new perspectives in the treatment of neurogenic $\mathrm{HO} .{ }^{13}$ The incidence of $\mathrm{HO}$, found in the literature, varies between $16 \%$ and $53 \%$, becoming, however, especially high in patients exposed to a previous risk condition (such as spinal cord injury

All the authors declare that there is no potential conflict of interest referring to this article.

1. Universidade Estadual de Campinas, Campinas, SP, Brazil

Work performed at the Laboratory of Biomechanics and Rehabilitation of the Locomotor System, Hospital das Clínicas, Universidade Estadual de Campinas and Nuclear Medicine Service, Universidade Estadual de Campinas, Campinas, SP, Brazil

Correspondence: Virgílio Dario, Rua Tessália Vieira de Camargo, 126, Cidade Universitária "Zeferino Vaz", Campinas, SP, Brazil. 13083-887. virgiliodario@hotmail.com 
and total hip arthroplasty). The discrepancy between these incidence rates reported in the literature is due to several factors such as: the population studied, the duration of the studies, the methods used for data collection and the procedures adopted in each center.

In cases of neurogenic origin, the hips are the parts with the highest prevalence of $\mathrm{HO}$, while the knees are less frequently affected..$^{14}$ However, heterotopic ossification can occur in many parts in the body such as elbows, shoulders, fractures in general or injuries in soft tissue. ${ }^{10}$

The primary method of $\mathrm{HO}$ classification was developed by Brooker et al..$^{15}$ and it is based on anteroposterior radiographs of the pelvis, having originally been described for injuries occurring after hip arthroplasty. (Chart 1)

Many authors have questioned the reliability and validity of this method. ${ }^{16}$ Therefore, other methods have been developed, as proposed by Della Valle et al., ${ }^{17}$ a system composed of three steps: Grade A (hips without $\mathrm{HO}$ and hips with no ossification islands up to $1 \mathrm{~cm}$ long - Brooker Grade I; Grade B (hips with at least one ossification island of over $1 \mathrm{~cm}$ or pelvis with spurs in the hip or pelvis and at least $1 \mathrm{~cm}$ between opposing bone surfaces - Brooker Grade II , and Grade C (hip spurs and less than $1 \mathrm{~cm}$ between femur and pelvis - Brooker Grade III - or ankylosis of the hip - Brooker Grade IV.

Besides from signs of inflammation in the acute phase of neurogenic $\mathrm{HO}$, other symptoms such as reduced range of motion and articular stiffness can be present. ${ }^{18,19}$ The differential diagnosis in the early stages include: deep vein thrombosis (DVT), cellulitis, tumor calcinosis, variants of osteosarcoma, thrombophlebitis, soft tissue tumors, hematomas and local trauma. ${ }^{20-23}$ The diagnosis of $\mathrm{HO}$ can be done through imaging, depending on the phase of the disease. Generally, to confirm the diagnosis and evaluation of the extent and metabolic activity of ossifying injury, conventional radiography is performed, followed by three-phase bone scintigraphy. It is also possible to use computerized tomography. ${ }^{15,23}$ Laboratory tests may be performed to exclude other pathologies.

Currently, we rely on the development of hybrid technologies for a more appropriate image diagnostic. The single-photon emission computed tomography (SPECT), in combination with computed tomography multiple cuts (CT) allows the early detection of subtle and non-specific abnormalities on bone scan and interpret them as focal pathology areas. ${ }^{24}$

SPECT/CT is the combination of both previously mentioned techniques. It uses a CT scanner associated with gamma cameras in a single structure. Collimators of different energy levels can be adopted according to the type of image to be generated. Processing occurs by the use of software able to

Chart 1. Classification proposed by Brooker et al.15 according to radiologic aspects of injury.

\begin{tabular}{|c|l|}
\hline Grade I & Ossification islands around the hip \\
\hline Grade II & $\begin{array}{l}\text { Bone projection of pelvis or proximal femur with at least } 1 \mathrm{~cm} \\
\text { away from the opposite surface }\end{array}$ \\
\hline Grade III & $\begin{array}{l}\text { Bone projection of pelvis or proximal femur reducing space } \\
\text { between opposite surface lower than } 1 \mathrm{~cm}\end{array}$ \\
\hline Grade IV & Hip ankylosis \\
\hline
\end{tabular}

Acta Ortop Bras. 2014;22(1):12-6 mitigate and correct the data collected. Meanwhile, a resolution recovery algorithm is applied to correct the image blurs when a structure is a few inches from the colimador. ${ }^{24}$ The SPECT/CT method with the radiopharmaceutical methylene diphosphate labeled with technetium-99 metastable (MDP-99mTc) allows precise anatomic location of areas with osteoblastic activity by merging images of three-dimensional computed tomography scans with the same device, with the patient in the same position.

$\mathrm{HO}$ is a common complication in patients victim of spinal cord injury. The advances made in the study of its pathophysiology, rehabilitation and new types of treatment provide new hope for the treatment of this clinical condition. ${ }^{25}$ The ossification process can begin and be diagnosed early in the first weeks after trauma. It can often occur between the first four weeks, being more common during the second month after the injury, although it also occurs within one year after the accident. ${ }^{7}$

It can be difficult in some cases to correctly diagnose $\mathrm{HO}$ and it may often go unnoticed or be confused with cancer, fibromatosis, among others. Delays in the disease identification and erroneous conclusions can cause pain and suffering to patients and families at risk of aggravating the disease. It is very important to initially suspect of the diagnosis of $\mathrm{HO}$ from the first contact with the patient. Despite all limitations that can be found in various health services, these difficulties should not limit or delay the intervention once the diagnosis is primarily clinical. ${ }^{26}$ Currently, the most effective treatment is by surgical resection, which should occur when there is bone maturation (usually 6-9 months after installation). However, this method has risks such as soft tissue injuries and recurrences and should be used only when there are restrictions on movement of the pelvis. Furthermore, resection may cause excessive bleeding, particularly in the femur, leading to increased morbidity and mortality. For this reason it is encouraged to search for new types of prophylaxis and establish the true therapeutic action of the chosen treatment and its side effects, enabling decision making for certain types of prophylactic therapy or against its use. ${ }^{8}$

Prophylactic treatment can be done mainly by non-steroid anti-inflammatory drug (NSAID) and radiotherapy. Its efficacy is controversial and there is no consensus about the only advantage of radiotherapy. Several studies have been conducted regarding the use of prophylactic indomethacin, however, their effectiveness has not yet been attested. ${ }^{8}$

It is necessary to provide more opportunities for slowing the progression of $\mathrm{HO}$ in injured patients. This prevents onset and worsening of deformities in affected individuals as well as enabling the establishment of prevention and treatment of $\mathrm{HO}$, for what it is absolutely necessary the early diagnosis of the disease in the patient with spinal cord injury.

The association between the onset of $\mathrm{HO}$ and the appearance of patient comorbidities on injured spinal cord, such as autonomic dysreflexia and DVT. This is an important complication due to its relationship with pulmonary thromboembolism (PTE) that can lead immediately to death. About one third of patients with PTE present symptoms of DVT in lower limbs. ${ }^{17}$

Due to reduced range of motion, some cases may present with ankylosis of the pelvis joint, contributing thus, to venous stasis in the lower limbs, therefore predisposing to DVT and pressure ulcers. It is described that the physiopathogenesis of DVT in 
$\mathrm{HO}$ is not only related to vascular stasis triggered by the mass effect of $\mathrm{HO}$, but also to an inflammatory mechanism. ${ }^{6}$

Therefore, it is essential to early and active pursuit $\mathrm{HO}$, in order to identify patients at higher risk for these related comorbidities, which also enable the development of prevention projects that lessened the morbidity and mortality of patients with spinal cord injury.

The use of SPECT/CT enables a precise anatomical diagnosis of $\mathrm{HO}$, being superior to other imaging methods, such as radiography and computed tomography. Moreover, SPEC/CT is able to determine the maturation of $\mathrm{HO}$, showing whether resection would be safe.

This study aims to evaluate and classify the maturity and bone metabolism in neurogenic heterotopic ossification in patients with spinal cord injury using SPECT/CT examination with MDP_ ${ }^{99 m} \mathrm{TC}$ as radiopharmaceutical that measures osteoblastic activity, because it integrates with the bone matrix to mimic phosphate by osteoblasts.

The main objective of this study is to evaluate the stage of maturation and metabolism of neurogenic heterotopic ossification by SPECT/CT examination, defined establishing the status of injury. To perform the study, the maturity status of each respective newly formed bone was related to Brooker classification chart.

\section{MATERIALS AND METHODS}

This study analyzes the results from SPECT/CT in patients with paraplegia and tetraplegia. The process aggregated patients of Hospital de Clinicas (HC), Universidade Estadual de Campinas (Unicamp), SP, Brasil.

This research project was approved by the Local Ethics Committee of the Faculdade de Ciências Médicas (FCM), Unicamp. All patients that underwent SPECT/CT were aware of the risks inherent to the exam and signed an informed consent term routinely used by the Serviço de Medicina Nuclear, HC (Unicamp). For this study, medical records of 12 patients with spinal cord injury at Hospital das Clínicas, Unicamp, were used, all cataloged from the ASIA protocol (deficiency scale of the American Spinal Injury Association) in complete lesion (A) or Incomplete (B, C, $D)$, that have been treated at the Laboratory of Biomechanics and Rehabilitation of the Locomotor System.

Once the choice of patients for the study was completed, all of them were duly informed and agreed to be included in the study, signing an informed consent form.

For SPECT/CT examination, participants provided some preliminary information to draw a profile of each patient, such as:

- Gender (male or female)

- Age; injury level;

- Asia;

- Cause of the injury;

- Injury time;

- The data having been shown in a chart.

Thus, patients were directed to SPECT/CT examination, a procedure performed by Serviço de Medicina Nuclear, HC, Unicamp, appliance Symbia T SPECT/CT Siemens where they received 1110 Megabecquerels (Mbq) of MDP99mTc intravenously. Planar imaging of blood flow (images every 2 seconds for 80 seconds) and balance (static image with 500,000 counts, matrix 256x256 pixels) of the pelvis immediately after, and 3 hours after injection, performed whole-body scans in anterior and posterior projections, with a $12 \mathrm{~cm} / \mathrm{min}$ speed, static images and SPECT/CT (with detectors in $360^{\circ}$ configuration, 20 seconds per projection, 60 projections per detector), pelvis and other areas of interest. The planar images were recorded partly in a Millennium MG gamma camera from General Electric, with the same parameters, according to the service logistics.

\section{Inclusion Criteria}

1. Patients para/tetraplegic with an established diagnosis of $\mathrm{HO}$ spinal cord after injury, i.e., upper motor neuron lesion with levels above $\mathrm{T} 12$.

2. The development of $\mathrm{HO}$ should be secondary to spinal cord injury, and the patient should have not suffered mechanical trauma in the site where $\mathrm{HO}$ developed. This, thus, excludes the traumatic factor from triggering the process.

\section{Patients with lesion for over one year.}

The results from SPECT/CT were verified from the respective radioisotope uptake assuming that, in the region where there is more uptake of radioisotope, there will be more osteoblastic activity, featuring the lesion areas of heterotopic ossification activity. Conversely, areas of heterotopic ossification with little radioactivity uptake characterize mature lesions. Furthermore, the result of Brooker classification was also considered as an important relationship since, from this analysis, it is possible to identify the likely progression of $\mathrm{HO}$ from grade II to grade III, for example, by reducing or even preventing ankylosis of joints and surgical procedures.

For this study, there were established statistics to illustrate the most common sites affected by $\mathrm{HO}$, as well as patient's age, and ASIA classification.

All data collected were grouped into a spreadsheet in Microsoft Excel 2010 and were forwarded to statistical analysis.

\section{RESULTS}

Of the 12 patients (16 pelves) who had heterotopic ossification in the hip and participated in the study, all were male, aged between 25 and 59 years, with a mean age of 39 years.

The level of spinal cord injury in these patients occurred between C4 to T8, being $63.7 \%$ in the thoracic spine and $36.3 \%$ in the cervical spine. (Figure 1)

Among the patients studied, 11 (90.9\%) were classified as ASIA A, and only one patient (9.1\%) was classified as ASIA B. (Figure 2)

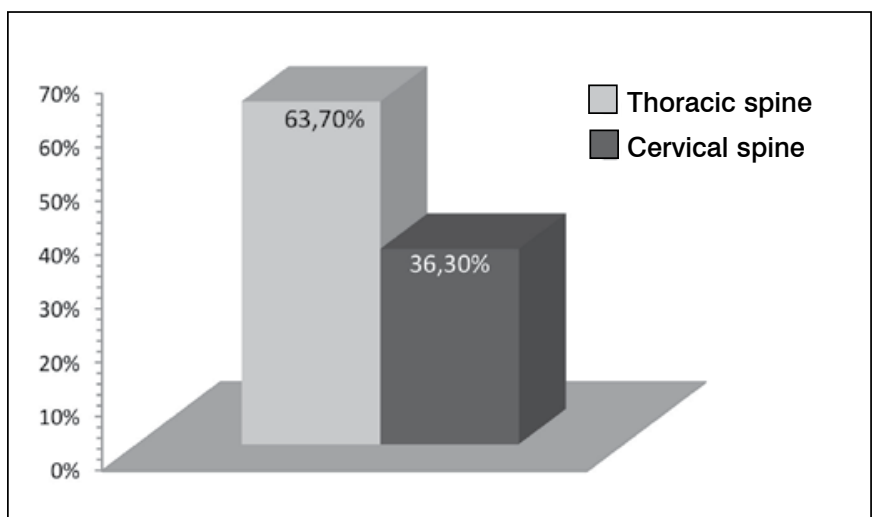

Figure 1. Level of spinal cord injury. 
The causes of spinal cord injury were motorcycle accidents $(72.8 \%)$, injury by firearms (18.2\%) and fall from heights (9\%). (Figure 3)

The time of spinal cord injury ranged from 3-18 years, where $45.5 \%$ had spinal cord injury for less than ten years.

Of the 16 pelves studied that showed heterotopic ossification at the X-Ray, only two (12.5\%) showed marked osteoblastic activity. Five pelves $(31.25 \%)$ showed moderate activity; three (18.75\%) mild activity; and six hips (37.5\%) showed absence of osteoblastic activity in the SPECT/CT exam. (Figure 4)

\section{DISCUSSION}

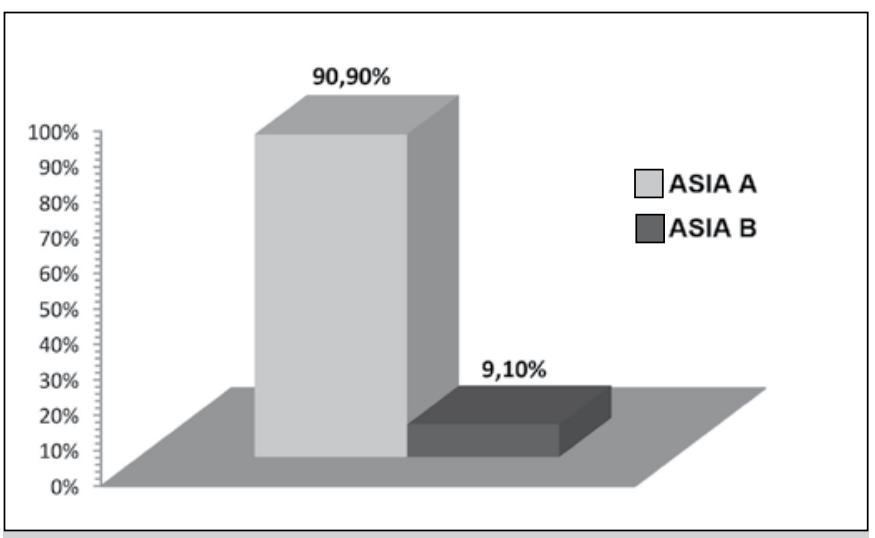

Figure 2. Classification of spinal cord injury.

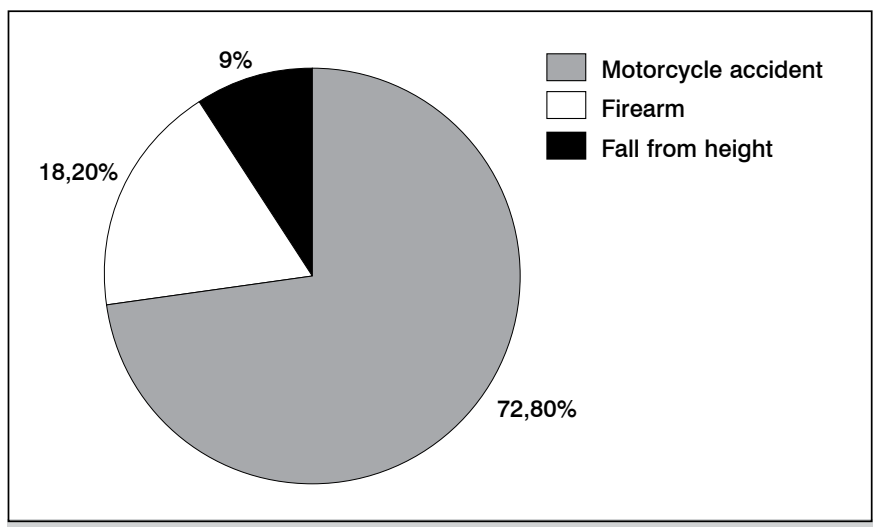

Figure 3. Causes of spinal cord injury.

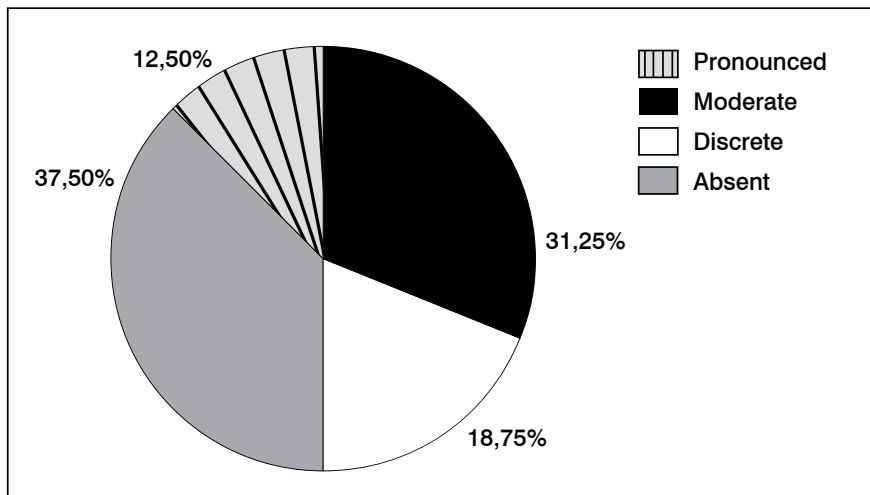

Figure 4. Osteoblastic activity in SPEC/CT.
Heterotopic ossification is a complication possibly observed in patients with spinal cord lesions. ${ }^{7}$ It can affect any joint, most commonly the hip. (Figure 5) It can limit the range of motion hampering, thus, the rehabilitation of these patients, since it undermines the position change, bed transfer and placement in the sitting position. ${ }^{1}$ Preventing these disease with anti-inflammatory drugs such as indomethacin and radiotherapy are controversial in the literature and still have their role questionable, which requires new and more detailed studies to establish the use of such measures as indisputable tools on $\mathrm{HO}$ prevention. ${ }^{8}$ In this scenario, the use of surgical resection remains as the treatment of choice since $\mathrm{HO}$ is established, remembering, however, that the surgical treatment of this entity is associated with intense intra-operative bleeding and high rates of relapse. ${ }^{21}$ It is believed that relapse is associated with the presence of osteoblastic activity in the $\mathrm{HO}$ focus at the time of resection. In other words, remaining osteoblastic cells would be responsible for recurrence, similarly to what happens with an incomplete resection of a neoplasm. This fact leads some authors to consider one $\mathrm{HO}$ a pseudotumoral injury.

This study was performed using SPECT/CT to determine osteoblastic activity in patients with spinal cord injury presenting with HO. (Figure 6) The uptake was ranked as: absent, mild, moderate, and severe. In the sample used, none of the patients underwent resection, because they had a functional range of motion. However, it is believed that the degree of uptake is probably related to the risk of relapse of the resected lesions, because the higher the activity, the more osteoblasts producing bone matrix will be present.

Analyzing the results obtained, it can be said that not all hips with $\mathrm{HO}$ show higher osteoblastic activity. Furthermore, no direct relationship between time and level of spinal cord injury and the degree of maturation of $\mathrm{HO}$ in SPECT/CT was found. However, we cannot say that the absence of scintigraphic uptake in the focus of $\mathrm{HO}$ will ensure resection without relapse. (Figure 7) Eventually, latent osteoblasts can be reactivated by inflammation due to the surgical aggression. Therefore, radiotherapy is widely used postoperatively in order to destroy the remaining or latent osteoblasts, reducing relapse rates. ${ }^{18}$

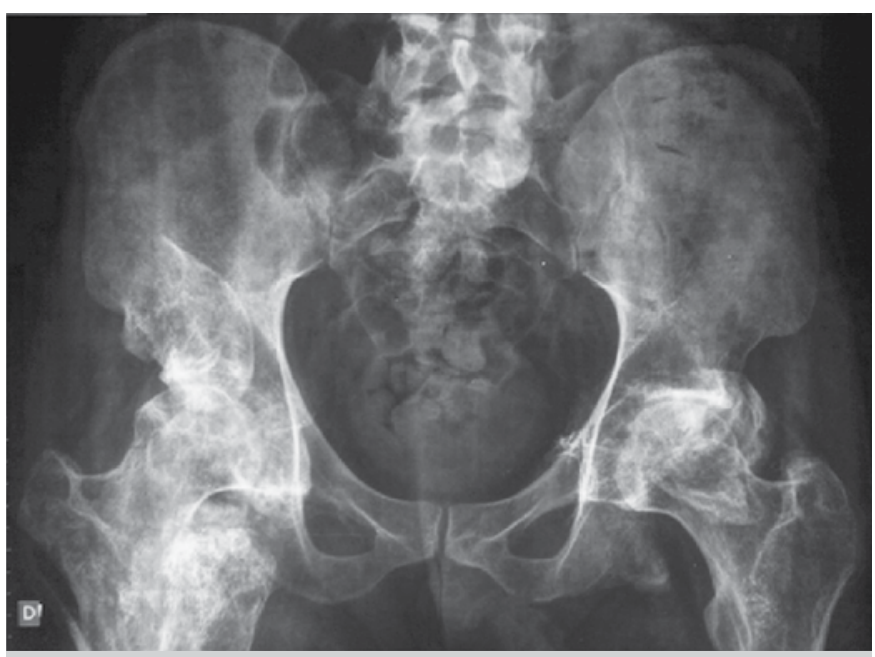

Figure 5. Pelvis radiography showing heterotopic ossification in both hips 

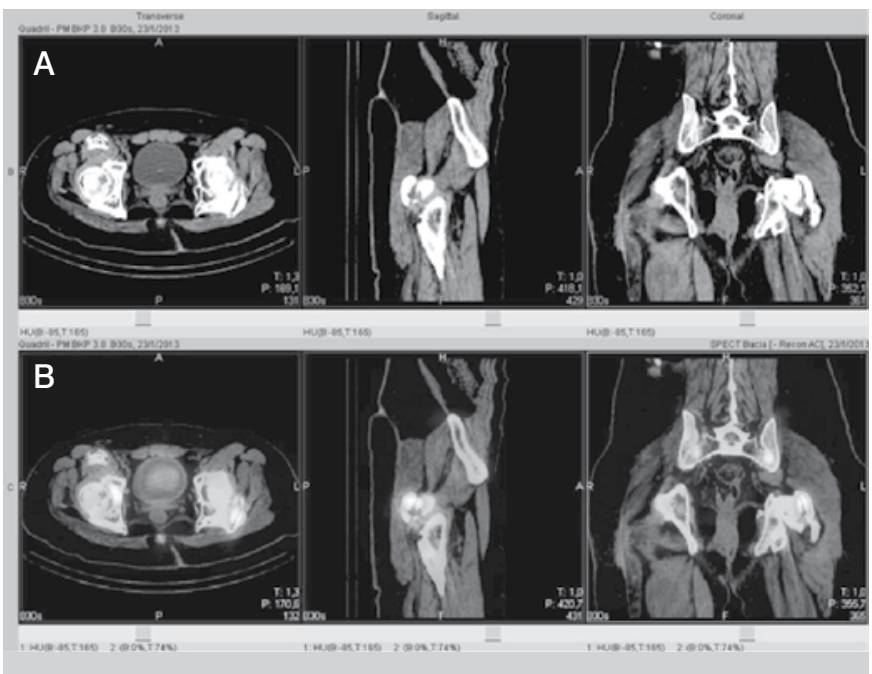

Figure 6. CT scan images $(A)$ and the same images added to bone scintigraphy (B), showing moderate captation in both heterotopic ossifications (same patient as from Figure 5).

\section{CONCLUSION}

$\mathrm{HO}$ is a detrimental clinical condition to rehabilitation and care of patients with spinal cord injury, hindering their social interaction. SPECT/CT helps to determine which patients shall present higher risk of relapse after resection, showing to be a good test in the preoperative evaluation. A study in patients with indication for resection and previous SPECT/CT exam can corroborate

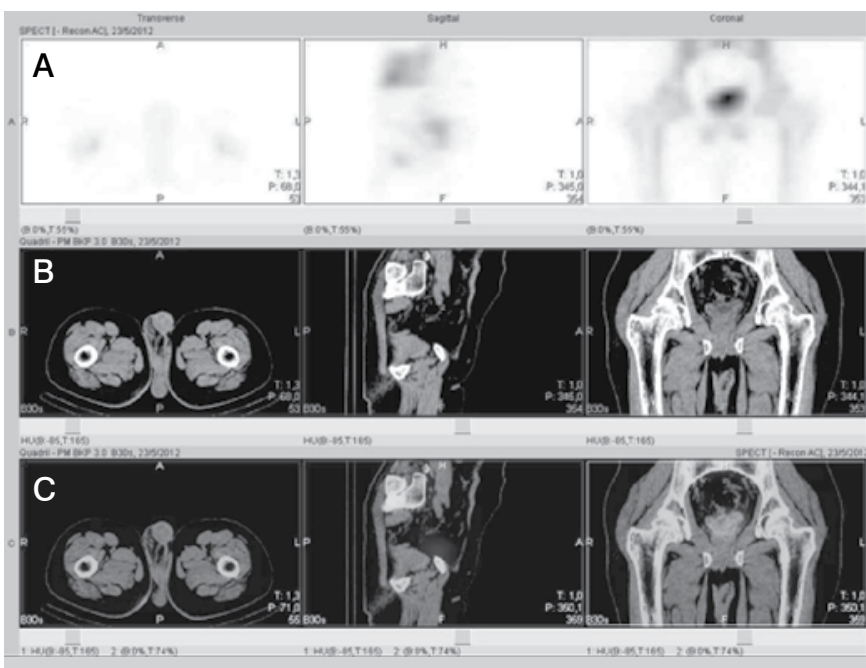

Figure 7. Scintigraphy images (A), CT scan images (B) and SPECT/CT images showing heterotopic ossification $(C)$ without increase of radiopharmaceuticals intake.

the results of this study, making this test a valuable resource to determine the postoperative prognosis.

\section{ACKNOWLEDGEMENTS}

The authors wish to thank the physiotherapists Eloza Regina Machado Ferreira Braga de Azevedo and Karina Cristina Alonso for their assistance in patients selection.

\section{REFERENCES}

1. Wharton GW, Morgan TH. Ankylosis in the paralyzed patient. J Bone Joint Surg Am. 1970;52(1):105-12.

2. Orzel JA, Rudd TG. Heterotopic bone formation: clinical, laboratory, and imaging correlation. J Nucl Med. 1985;26(2):125-32.

3. Citak M, Suero EM, Backhaus M, Aach M, Godry H, Meindl R, et al. Risk factors for heterotopic ossification in patients with spinal cord injury: a casecontrol study of 264 patients. Spine (Phila Pa 1976). 2012;37(23):1953-7.

4. Melo RM, Mendonça MQ, Mendonça ET, Mendonça EQ. Ossificação heterotópica em saco herniário incisional. Rev Col Bras Cir. 2012;39(2):151-4.

5. Garland DE. A clinical perspective on common forms of acquired heterotopic ossification. Clin Orthop Relat Res. 1991;(263):13-29.

6. Coelho CV, Beraldo PS. Risk factors of heterotopic ossification in traumatic spinal cord injury. Arq Neuropsiquiatr. 2009;67(2B):382-7.

7. Castro AW, Greve JMD. Ossificação heterotópica em pacientes com lesão medular traumática: associação com antígenos do sistema HLA. Acta Ortop Bras. 2003;11(2): 102-9.

8. Leite NM, Faloppa F. Ossificações heterotópicas. Projeto Diretrizes. 2007;7(35):1-9.

9. Athanazio DA, Carvalho ALL, Silva NO, Athanazio PRF. Heterotopic intraabdominal ossification: report of a case and review of the literature. J Bras Patol Med Lab. 2009;45(2):125-30.

10. Shehab D, Elgazzar AH, Collier BD. Heterotopic ossification. J Nucl Med. 2002;43(3):346-53.

11. Mavrogenis AF, Guerra G, Staals EL, Bianchi G, Ruggieri P. A classification method for neurogenic heterotopic ossification of the hip. J Orthop Traumatol. 2012;13(2):69-78.

12. Chalmers J, Gray DH, Rush J. Observations on the induction of bone in soft tissues. J Bone Joint Surg Br. 1975;57(1):36-45.

13. Ahn J, Serrano de la Pena L, Shore EM, Kaplan FS. Paresis of a bone morphogenetic protein-antagonist response in a genetic disorder of heterotopic skeletogenesis. J Bone Joint Surg Am. 2003;85(4):667-74.

14. Vanden Bossche L, Vanderstraeten G. Heterotopic ossification: a review. J Rehabil Med. 2005;37(3):129-36.

15. Brooker AF, Bowerman JW, Robinson RA, Riley LH Jr. Ectopic ossification following total hip replacement. Incidence and a method of classification. $J$ Bone Joint Surg Am. 1973;55(8):1629-32.

16. Cohn RM, Schwarzkopf R, Jaffe F. Heterotopic ossification after total hip arthroplasty. Am J Orthop (Belle Mead NJ). 2011;40(11):E232-5.

17. Della Valle AG, Ruzo PS, Pavone V, Tolo E, Mintz DN, Salvati EA. Heterotopic ossification after total hip arthroplasty: a critical analysis of the Brooker classification and proposal of a simplified rating system. J Arthroplasty. 2002;17(7):870-5.

18. Taricco DL, Araujo IF, Juliano Y, Ares MJJ, Cristante ARL. Uso da radioterapia na ossificação heterotópica imatura em pacientes com lesão medular. Acta Fisiatr. 2008;15(3):44-8.

19. Wick L, Berger M, Knecht H, Glücker T, Ledermann HP. Magnetic resonance signal alterations in the acute onset of heterotopic ossification in patients with spinal cord injury. Eur Radiol. 2005;15(9):1867-75.

20. Venier LH, Ditunno JF Jr. Heterotopic ossification in the paraplegic patient. Arch Phys Med Rehabil. 1971;52(10):475-9.

21. Chantraine A, Minaire P. Para-osteo-arthropathies. A new theory and mode of treatment. Scand J Rehabil Med. 1981;13(1):31-7.

22. Laurin NR, Powe JE, Pavlosky WF, Driedger AA. Multimodality imaging of early heterotopic bone formation. Can Assoc Radiol J. 1990;41(2):93-5

23. Hartmann APBJ, Ximenes ARS, Hartmann LCG, Fernandes ARC, Natour J, D'Ippolito G. Diagnóstico por imagem na avaliação da ossificação heterotópica. Rev Bras Reumatol. 2004;44(4):291-3.

24. Scharf S. SPECT/CT imaging in general orthopedic practice. Semin Nucl Med. 2009;39(5):293-307.

25. Ferreira DBJ, Lippelt HC, Cliquet Júnior AC. Estimulação elétrica neuromuscular na reversão da ossificação heterotópica. Acta Ortop Bras. 2006;14(2):72-4.

26. Garcia-Pinzas J, Wong JE, Fernández MA, Rojas-Espinoza MA. Fibrodysplasia ossificans progressiva: diagnosis in primary care. Rev Paul Pediatr. 2013;31(1):124-8. 